\title{
Evaluation of Success Rate of Exogenous Obesity Management with an Intensive Follow-up Program
}

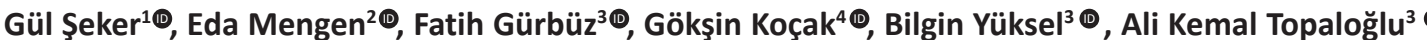

Cite as: Şeker G, Mengen E, Gürbüz F, Koçak G, Yüksel B, Topaloğlu AK. Evaluation of success rate of exogenous obesity management with an intensive follow-up program. Trends in Pediatrics 2021;2(3):114-21.

Received: 08 February 2021

Accepted: 11 June 2021

Publication date: 28 September 2021

Keywords: Exogenous obesity, body mass index, body fat percentage, diet, exercise

Gül Şeker

Dokuz Eylül University Faculty of Medicine, Department of Pediatric Gastroenterology 35060, Izmir - Turkey

ORCID: 0000-0002-3829-4978

gul_cirkin@hotmail.com

\begin{abstract}
Objective: Obesity critically affects the quality and expectancy of life with its physiological, hormonal, metabolic, and social aspects. This study has assessed the success rate of exogenous obesity management consisting of lifestyle changes with an intensive follow-up in prepubertal children.

Methods: Twenty-two obese prepubertal children between ages 4 and 9 years were enrolled in this study. Eating habits were surveyed, and individually tailored diet programs were introduced. Additionally, an exercise coach prepared individualized exercise programs. Patients were recalled monthly for six months. At each monthly visit, weight, height, BMI, waist circumference, body fat percentages were measured, and compliance with the diet and exercise programs was reviewed. Wilcoxon signed-rank test was used for statistical analysis.

Results: The patients showed statistically significant reductions in $B M I$, waist circumference, and body fat percentage $(p<0.001$ for each).

Conclusion: This study demonstrates that in prepubertal obese children, lifestyle changes implemented by intensive follow-up and monitoring could increase the success rate of exogenous obesity management.
\end{abstract}

\section{INTRODUCTION}

Obesity is well known to affect the quality and expectancy of life with its detrimental ramifications in physiological, psychological, hormonal, metabolic, and social dimensions. The incidence of obesity is globally increasing among both adults and the pediatric population. ${ }^{1}$ Obesity is a multifactorial condition that arises from an imbalance between energy intake and energy consumption. ${ }^{2}$ Obesity is described by the World Health Organization (WHO) as an increase in the amount of body fat to a level that impairs health. ${ }^{3}$

While there are many known and potential causes for childhood obesity, an underlying disorder cannot 
be identified in most cases. This form of obesity is called "simple" or "exogenous" obesity and is the most common cause of childhood obesity. When obesity is caused by endocrinological, genetic, or other conditions, it is called "secondary" or "endogenous" obesity. These factors affect the basic equation of "energy intake equals to energy usage," and in exogenous obesity, energy intake exceeds energy usage. ${ }^{6}$

Several severe health issues are associated with childhood obesity. Most remarkably, more than half of the individuals who are obese in adolescence become obese adults if obesity is not seen as a severe condition to be treated by families or health care providers. ${ }^{7}$ Moreover, increasing incidence of obesity has led to raised occurrences of chronic diseases typically seen in adults, such as Type 2 diabetes, metabolic syndrome, and hypertension in children.

Lifestyle modification is the only option in managing childhood obesity as neither bariatric surgery nor pharmacological interventions are recommended in children with obesity. Thus, we hypothesized that childhood obesity could be better managed with a closer clinical follow-up. In this study, we have observed a higher success rate in the management of exogenous obesity by an intensive follow-up after lifestyle interventions in prepubertal patients with exogenous obesity. However, this required close and sustained cooperation of the families.

\section{MATERIAL and METHODS}

We enrolled 22 consecutive prepubertal girls and boys aged 4-9 years who were diagnosed with exogenous obesity in the pediatric endocrinology outpatient clinic. Obesity was defined as BMI >2 SD score, according to the World Health Organization criteria. ${ }^{4}$ Standard deviation (SD) scores for weight, height and BMI were determined using the reference created for the Turkish population by Neyzi et al. ${ }^{5}$ The pubertal stage of each case was determined according to Tanner pubertal staging. ${ }^{8}$ The patients and families were interviewed about the age of onset of obesity, birth weight, gestational age, duration of breastfeeding, duration of TV watching, eating habits and choices, family history of obesity, monthly income and educational status of the parents.

Twenty obese children (16 girls, and six boys) were enrolled. The ethics committee of the Cukurova University, Faculty of Medicine, approved this study and informed consents were obtained from legal guardians. We had initially planned 80 patients as the study population. However, 58 (72.5\%) of 80 patients dropped out in the second or third months of the study.

Weight, height, body mass index (BMI), waist circumference, body fat percentage, and biochemical parameters were determined. Body mass index (BMI) was calculated by dividing body weight $(\mathrm{kg})$ by height squared $\left(\mathrm{m}^{2}\right)^{4,5}$ Waist circumference (WC) was measured at the end of a gentle expiration in a patient without clothing using a non-stretchable tape with sensitivity of $0.1 \mathrm{~cm}$, between the midpoint of the lowest rib cage and the iliac crest. WC percentiles and SD scores were calculated according to age and gender regarding the data for Turkish children. ${ }^{9}$ All measurements were made by the same investigator (GS).

Body fat percentage measurements were made by determining the level of visceral adipose tissue (VAT) and body fat percentage (FM\%) using a bioelectrical impedance measurement device (BIA, TANITA BC $420 \mathrm{MA})$. The bioelectrical impedance analysis method is based on the electrical permeability differences between the adipose tissue and other tissues. We instructed families that foods and drinks should not be consumed for 4 hours and physical exercise must not be performed for 12 hours preceding the measurements.

An individualized nutrition plan was generated for each patient. Patients received individualized exercise plans prepared by the same investigator, who is a registered exercise coach (GK). The patients were scheduled for a monthly follow-up for a 6-month-period. Weight, height, BMI, waist circumference, and body fat percentage were measured at each visit. Compliance with the nutritional and exercise program was reviewed. At the end of the sixth month, measurements were re-evaluated and compared. 
Laboratory tests: Venous blood samples were obtained following 8-hour fasting. Fasting blood glucose (FBG), fasting insulin, C-peptide, HbA1c, serum lipid profile, total cholesterol, High Density Lipoprotein (HDL), Low Density Lipoprotein (LDL), triglycerides, fT4, and thyroid stimulating hormone (TSH) values were determined.

The diet program: Daily energy requirement was calculated for each patient according to his or her age, sex, and target weight. The diet list was generated for each patient to include necessary nutrients according to patients' age and socioeconomic and cultural background as follows: $50-55 \%$ of the daily energy requirement from carbohydrates, $15-20 \%$ from proteins, and $30 \%$ from fats. Previous nutritional habits were ascertained, and healthy alternatives were specified. Patients were given a balanced diet according to their target weight. ${ }^{10,11} \mathrm{~A}$ registered pediatric dietitian followed up patients during and after the study.

Exercise program: All 22 patients were included in the home exercise program. An experienced exercise trainer created the exercise program. Before the exercise program, body composition analysis was conducted using TANITA BC $420 \mathrm{MA}$, and waist circumference was measured. The type of exercise given to the home exercise group was chosen as aerobic exercise (walking, cycling, swimming, climbing stairs, dancing) and strength exercise using their own weight. An exercise follow-up chart was created to chronicle patients' workout sessions. Each child received a written monthly exercise plan and an exercise follow-up chart. The exercise follow-up chart would make the children feel in control, keep them motivated and let the exercise coach follow up the patients. Children were invited every month and evaluated for exercise compliance. Children having problems with compliance were given advice on possible solutions. ${ }^{12}$

Statistical Analysis: SPSS Software package v20.0 was used to analyze the data statistically. Categorical measurements were summarized as number and percentage, whereas continuous measurements were summarized as mean and standard deviation (or median, minimum-maximum where applicable). In the comparison of pretreatment and posttreatment values at the 1 st and 6 th months, Wilcoxon signed ranks test was used, as parametric test assumptions were not met with number of participants fewer than 30. A significance level of 0.05 was set. ${ }^{13}$

\section{RESULTS}

Comparisons of the physical measurements at the 1st and 6th months are presented in Table 1. The waist circumference and BMI measurements were significantly lower in the 6th month after treatment, while height measurement was significantly higher. However, the weight measurements were not statistically different.

Comparisons of the body fat percentages at 1 and 6

Table 1. Comparisons of the physical measurements at 1 and 6 months after treatment $(n=22$ )

\begin{tabular}{|c|c|c|c|c|c|c|c|c|c|}
\hline & & \multirow[b]{2}{*}{ Mean } & \multirow[b]{2}{*}{$\begin{array}{l}\text { Standard } \\
\text { deviation }\end{array}$} & \multirow[b]{2}{*}{ Minimum } & \multirow[b]{2}{*}{ Maximum } & & \multirow[b]{2}{*}{$p$} \\
\hline & & & & & & 25th & $\begin{array}{c}\text { 50th } \\
\text { (Median) }\end{array}$ & 75th & \\
\hline \multirow[t]{2}{*}{ Height (cm) } & 1. month & 131.173 & 9.7894 & 109.0 & 147.0 & 127.750 & 132.000 & 138.500 & \multirow[t]{2}{*}{$<0.001$} \\
\hline & 6. month & 134.827 & 10.1155 & 111.5 & 152.0 & 130.900 & 136.000 & 142.250 & \\
\hline \multirow[t]{2}{*}{ Weight (kg) } & 1. month & 41.841 & 8.6834 & 23.4 & 59.6 & 37.150 & 40.750 & 48.150 & \multirow[t]{2}{*}{0.144} \\
\hline & 6. month & 40.891 & 9.1703 & 22.0 & 59.0 & 33.600 & 41.450 & 45.325 & \\
\hline \multirow{2}{*}{$\begin{array}{l}\text { Waist } \\
\text { circumference }(\mathrm{cm})\end{array}$} & 1. month & 74.200 & 7.7364 & 65.0 & 90.0 & 67.750 & 74.000 & 79.000 & \multirow[t]{2}{*}{$<0.001$} \\
\hline & 6. month & 69.082 & 7.4180 & 58.0 & 81.0 & 63.000 & 67.000 & 77.250 & \\
\hline \multirow[t]{2}{*}{$\mathrm{BMI}\left(\mathrm{kg} / \mathrm{m}^{2}\right)$} & 1. month & 24.127 & 2.5921 & 19.7 & 29.6 & 22.375 & 24.100 & 25.825 & \multirow[t]{2}{*}{$<0.001$} \\
\hline & 6. month & 22.345 & 2.8475 & 17.3 & 28.0 & 20.500 & 22.000 & 24.400 & \\
\hline
\end{tabular}




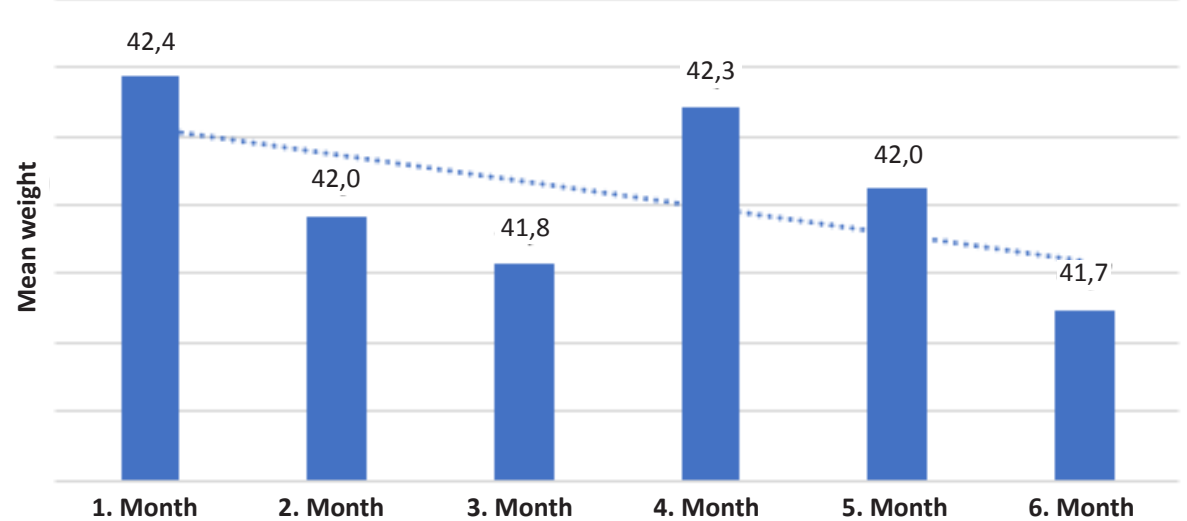

Figure 1. Changes in the weight measurements during the study period in girls $(n=16)$

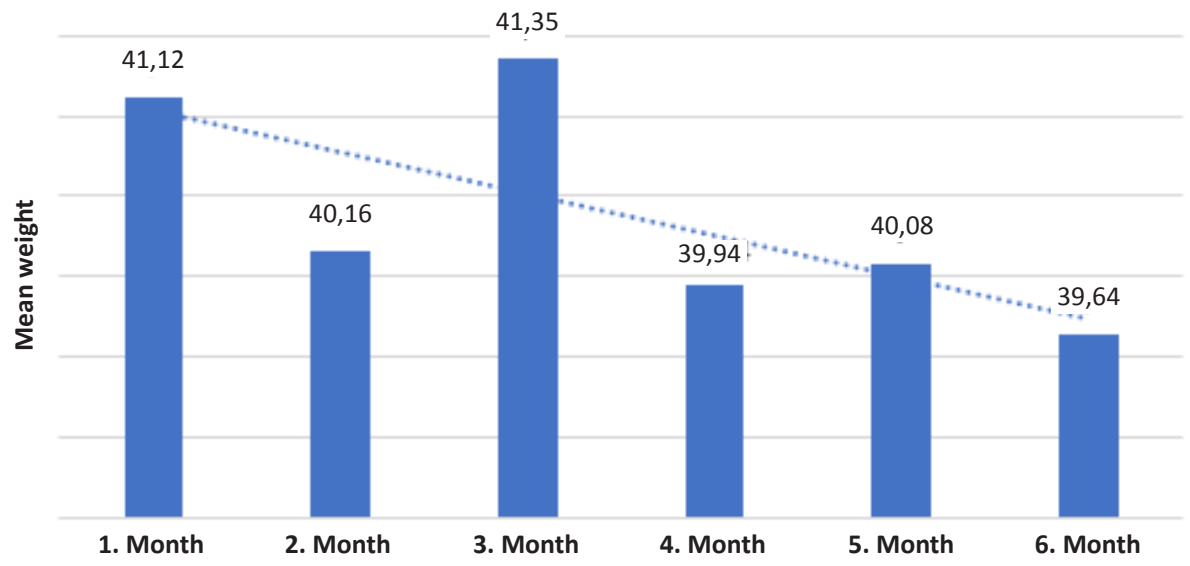

Figure 2. Changes in the weight measurements $d$ uring the study period in boys $(n=6)$

Table 2. Comparisons of the body fat percentages at 1 and 6 months after treatment $(n=22)$

\begin{tabular}{|l|c|c|c|c|c|c|c|c|c|} 
& & Mean & $\begin{array}{c}\text { Standard } \\
\text { deviation }\end{array}$ & Minimum & Maximum & 25th & $\begin{array}{c}\text { 50th } \\
\text { (Median) }\end{array}$ & 75th \\
\hline & & & & & & & \\
\hline
\end{tabular}

months after treatment are presented in Table 2. The body fat percentages were significantly lower in the 6th month.

Comparisons of the laboratory measurements at 1 and 6 months after treatment are presented in Table 3. No statistically significant difference was observed in any of the parameters.

\section{DISCUSSION}

Obesity is an energy metabolism disorder caused by excessive accumulation of fat in the body that may cause physical and psychological problems. Obesity and its serious complications have raised heightened interest in simple and effective methods to prevent and treat obesity. Lifestyle modification that includes 
Table 3. Comparisons of the laboratory measurements at 1 and 6 months after treatment $(n=22)$

\begin{tabular}{|c|c|c|c|c|c|c|c|c|c|}
\hline & & & & & & & Percentiles & & \\
\hline & & Mean & $\begin{array}{l}\text { Standard } \\
\text { deviation }\end{array}$ & Minimum & Maximum & 25th & $\begin{array}{c}\text { 50th } \\
\text { (Median) }\end{array}$ & 75th & $\mathbf{p}$ \\
\hline TSH (mIU/L) & 1. Month & 3.0527 & 1.09816 & 1.07 & 5.72 & 2.2175 & 3.1700 & 3.6825 & 0.543 \\
\hline & 6. Month & 2.8941 & 1.37619 & 1.05 & 6.49 & 1.9325 & 2.5300 & 3.5450 & \\
\hline Free T4 (ng/dL) & 1. Month & 1.1768 & .86666 & .61 & 4.63 & .8850 & .9600 & 1.0450 & 0.523 \\
\hline & 6. Month & .9236 & .12089 & .65 & 1.23 & .8500 & .9250 & .9825 & \\
\hline HbA1c (\%) & 1. Month & 5.359 & .4204 & 4.7 & 6.1 & 5.085 & 5.370 & 5.613 & 0.380 \\
\hline & 6. Month & 5.417 & .3957 & 4.9 & 6.1 & 5.053 & 5.385 & 5.823 & \\
\hline Glucose (mg/dL) & 1. Month & 85.36 & 7.762 & 72 & 98 & 79.75 & 83.00 & 92.25 & 0.985 \\
\hline & 6. Month & 85.41 & 4.717 & 79 & 94 & 80.75 & 85.50 & 89.25 & \\
\hline Insulin (IU) & 1. Month & 11.125 & 11.4256 & 2.1 & 53.0 & 4.460 & 8.735 & 13.188 & 0.465 \\
\hline & 6. Month & 9.483 & 7.7337 & 2.5 & 38.5 & 4.450 & 7.910 & 12.525 & \\
\hline HOMA IR (mmol/L) & 1. Month & 44.5 & 50.2 & 7.4 & 230.6 & 15.8 & 32.4 & 51.2 & 0.338 \\
\hline & 6. Month & 36.5 & 31.2 & 9.0 & 153.9 & 17.4 & 28.6 & 46.9 & \\
\hline Total cholesterol & 1. Month & 140.00 & 32.773 & 74 & 203 & 119.25 & 142.50 & 156.50 & 0.436 \\
\hline$(\mathrm{mg} / \mathrm{dL})$ & 6. Month & 136.18 & 37.821 & 30 & 198 & 114.00 & 136.50 & 172.25 & \\
\hline Triglyceride & 1. Month & 87.95 & 43.023 & 23 & 185 & 51.00 & 78.00 & 121.00 & 0.821 \\
\hline$(\mathrm{mg} / \mathrm{dL})$ & 6. Month & 82.33 & 31.819 & 29 & 133 & 57.50 & 79.00 & 114.00 & \\
\hline
\end{tabular}

diet, exercise, and behavioral motivation is the mainstay in all forms of exogenous obesity regardless of the patient age and availability of pharmacological or surgical interventions. Lifestyle modification is practically the only available method for obesity in prepubertal children. The main principles of nutritional management in obese children include decreasing calorie intake according to daily requirements and modification of eating habits. The goal of dietary treatment is to make patients reach their ideal weight and maintain this weight through healthy eating habits all their lives. In children, however, the goal of diet treatment varies with the severity of obesity. As long as the patient is not morbidly obese, the goal of treatment is to maintain the same body weight instead of weight loss. As the children become taller, BMI is expected to be normalized. ${ }^{14}$

A committee made up of pediatric obesity specialists has recommended a comprehensive staged-care approach for treating childhood obesity. ${ }^{15}$ Patients in our study would be classified in Stage 2 (structured weight management) for that stratification. The
Expert Committee stated that "monthly office visits are probably most appropriate at this level." They did not cite a study or provide data to substantiate this recommendation. However, this level of intense follow-up may not be available to most obese children. It is a well-known fact that management of obesity with lifestyle modification has a rather low success rate. In clinical practice, lifestyle interventions only reduce mean BMI by -1 to $-2 \mathrm{~kg} / \mathrm{m}^{2}$, and the long-term success rate (a decrease in BMI SD score of $<0.25$ ) at two years is $<10 \%{ }^{16}$ Thus, we hypothesized that lifestyle changes in the management of childhood obesity could be better implemented with a close and sustained clinical follow-up. In this study, we observed that patients with an intensive follow-up have encouraging results regarding the most critical obesity parameters such as BMI, waist circumference, and body fat percentage. Since each of our patients served as his/her own control in a prospective longitudinal set-up, our results are free from confounding variables, therefore scientifically valid and valuable.

We generated a nutritional plan suitable for the age, 
Table 4. Comparison of clinic parameters obtained before and 6 months after treatment

\begin{tabular}{|c|c|c|c|c|c|c|c|}
\hline & \multicolumn{3}{|c|}{ Standard follow-up group $(n=20)$} & \multicolumn{3}{|c|}{ Intensive follow-up group ( $n=22)$} & \multirow[b]{2}{*}{$\mathbf{P}$} \\
\hline & $\begin{array}{c}\text { Before } \\
\text { treatment } \\
\text { Mean } \pm S S\end{array}$ & $\begin{array}{c}6 \text { months after } \\
\text { treatment } \\
\text { Mean } \pm S S\end{array}$ & $\mathbf{P}$ & $\begin{array}{c}\text { Before } \\
\text { treatment } \\
\text { Mean } \pm S S\end{array}$ & $\begin{array}{c}6 \text { months after } \\
\text { treatment } \\
\text { Mean } \pm S S\end{array}$ & $\mathbf{P}$ & \\
\hline Height (cm) & $127.1 \pm 10.5$ & $130.1 \pm 10.2$ & 0.0001 & $131.2 \pm 9.8$ & $134.8 \pm 10.1$ & 0.0001 & 0.051 \\
\hline Height SDS & $1.0(-1.5-4.0)$ & $1.4(-0.7-4.6)$ & 0.0001 & $0.0(-1.3-3.1)$ & $0.6(-0.4-3.7)$ & 0.0001 & 0.273 \\
\hline Weight (kg) & $37.6 \pm 8.5$ & $40.8 \pm 8.5$ & 0.0001 & $41.8 \pm 8.7$ & $40.9 \pm 9.2$ & 0.144 & 0.0001 \\
\hline Weight SDS & $2.3(1.2-3.7)$ & $2.7(1.4-4.5)$ & 0.0001 & $2.0(1.1-3.4)$ & $2.0(0.2-3.1)$ & 0.068 & 0.0001 \\
\hline BMI $\left(\mathrm{kg} / \mathrm{m}^{2}\right)$ & $23.1 \pm 2.4$ & $24.1 \pm 2.5$ & 0.0001 & $24.1 \pm 2.6$ & $22.3 \pm 2.8$ & 0.0001 & 0.0001 \\
\hline BMI SDS & $2.2(1.1-3.3)$ & $2.4(1.4-3.9)$ & 0.005 & $2.2(1.3-3.1)$ & $1.9(0.1-2.8)$ & 0.0001 & 0.0001 \\
\hline Waist circumference (cm) & $68.7 \pm 5.7$ & $70.5 \pm 5.7$ & 0.0001 & $74.2 \pm 7.7$ & $69.1 \pm 7.4$ & 0.0001 & 0.0001 \\
\hline Waist circumference SDS & $3.1(1.1-5.7)$ & $3.4(1.8-6.3)$ & 0.0001 & $3.7(1.8-7.5)$ & $2.3(0.7-6.0)$ & 0.0001 & 0.0001 \\
\hline Body fat percentage $\%$ & $33.6 \pm 4.7$ & $36.2 \pm 4.7$ & 0.0001 & $35.5 \pm 4.4$ & $31.9 \pm 4.7$ & 0.0001 & 0.0001 \\
\hline
\end{tabular}

socio-economic status, and cultural tendencies of each patient in the intensive follow-up group. Nutritional habits were discussed with patients and their families. We recommended that the entire household should participate in healthy eating practices. We promoted natural and additive-free nutritional habits. In the monthly visits, we offered alternatives to food items that patients did not want to eat.

The combination of diet and exercise result in more weight loss than diet alone. In the long run, exercise is indispensable to maintain current weight. We followed up the exercise habits monthly by using an exercise follow-up chart. Thus, our patients saw their own progress and felt that they were in control. After the study was completed, we recommended that children continue exercise training all their lives.

In this study, we raised awareness through frequent control visits and thus achievement of weight loss and its maintenance more likely. In the standard clinical practice, diet and exercise recommendations are made, and patients are called for a follow-up control visits within 3-6 months. On the other hand, we monitored our patients every month and evaluated their compliance with the recommended lifestyle modifications. We predicted the difficulties in putting these lifestyle modifications into practice, and instead of waiting for six months according to the routine obesity care practice, we made the necessary interventions in time. This way, we ensured that the recommended lifestyle changes were implemented in our patients' lives in a most practical way. We managed this with the help of two critical professionals, namely, dietitian and training coach. The principal investigator (GS) was the primary contact person of patients and families. Another critical aspect of the study was that we involved at least one parent during follow-up visits, enlisting the whole family's help to put the lifestyle modifications into practice. Andreson et al., in support of our study, found that promoting positive relationships between parents/caregivers and children holds promise to prevent childhood obesity. ${ }^{17}$

The mechanisms that let intensive follow-up leading to better outcomes are unknown, but increased awareness, good relations with other professionals, addressing the needs in an expedited manner, answering questions in time, and positive motivation are thought to play essential roles.

As the weaknesses of this study, the number of study participants was lower than expected. Also, the high rate of drop-out at the beginning of the study underscored the crucial problem of motivation on behalf of patients and families in managing obesity.

\section{CONCLUSION}

Given the alarming global increase in the prevalence of childhood obesity and the unavailability of alternative treatment options like pharmacotherapy or bariatric surgery in prepubertal children, the 
question of how to better implement lifestyle changes becomes crucial. Our findings support a close, frequent, and sustained clinical follow-up with the help of nutrition and exercise professionals for the successful management of childhood obesity.

Ethics Committee Approval: Approval was obtained from the Non-Invasive Clinical Research Ethics Committee of Çukurova University Faculty of Medicine (Ethics Committee approval number: 28/14.02.2014). Conflict of Interest: The authors declared no potential conflicts of interest with respect to the research, authorship, and/or publication of this article.

Funding: The authors received no financial support for the research, authorship, and/or publication of this article.

Informed Consent: Parents of the patient provided informed consent to publish the report.

\section{REFERENCES}

1. Hintz RL. Management of disorders of size. In: Brook CGD, Hindmarsh PC, Clinical Pediatric Endocrinology 4th ed, United Kingdom: Blakwell Science, 2001;12440.

2. Donohoue PA. Obesity. In: Behrman RE, Kliegman RM, Jenson HB. Nelson Textbook of Pediatrics 17th ed. Philadelphia: W.B. Saunders, 2004;173-7.

3. World Health Organization: Obesity: Preventing and Managing the Global Epidemic Report of a WHO Consul- tation on Obesity. Geneva, World Health Organ Tech Rep Ser. 2000;894:1-253.

4. Onis M, Onyango AW, Borghi E, Siyam A, Nishida C, Siekmann J. Development of a WHO growth reference for school-aged children and adolescents. Bull World Health Organ 2007;85:660-7. https://doi.org/10.2471/BLT.07.043497

5. Neyzi O, Bundak R, Gökçay G, Günöz H, Furman A, Darendeliler $F$, et al. Reference values for weight, height, head circumference, and body mass index in Turkish children. J Clin Res Pediatr Endocrinol. 2015;7:280-93.

https://doi.org/10.4274/jcrpe.2183

6. Kandemir D. Obesity classification and clinical features. Katkı Journal of Pediatrics 2000;21:500-6.

7. Keskin M, Kurtoglu S, Kendirci M, Ataberk ME, Yazıcı C. Homeostasis model assesment is more reliable than the fasting glucose/insuline ratio and quantative insuline sensitivity check index for assessing insuline resistance among obese children and adolescents. Pediatrics 2005;115:500-3. https://doi.org/10.1542/peds.2004-1921

8. Quinn SF, Gosink BB. Characteristic sonografic signs of hepatic fatty infiltration. Am $\mathrm{K}$ Roentgenol. 1985;145:753-5.

https://doi.org/10.2214/ajr.145.4.753

9. Hatipoglu N, Ozturk A, Mazicioglu MM, Kurtoglu S, Seyhan S, Lokoglu F. Waist circumference percentiles for 7- to 17-year-old Turkish children and adolescents. Eur J Pediatr 2008;167:383-9. https://doi.org/10.1007/s00431-007-0502-3

10. Schling P, Löffler G. Cross talk between adipose tissue cell, impact on pathophysiology. News PhysiolSci. 2002;17:99-104. https://doi.org/10.1152/physiologyonline.2002.17.3.99

11. Prentice AM. Jebb SABeyond mass index. Obes Rev 2001;2:141-7. https://doi.org/10.1046/j.1467-789x.2001.00031.x

12. Albinson J, Andrew G. Child in Sport and Physical Activity. 1976.

13. Şimşek F, Betül U, Merih B, Gülnar SB, Adıyaman P, Öcal G.The prevalence of obesity in a primary school and high school in Ankara. Ankara Journal of Medicine. 2005;58:163-6.

14. Cuda SE, Censani M. Pediatric obesity algorithm: A Practical approach to obesity diagnosis and management. Front Pediatr. 2019;6:43. https://doi.org/10.3389/fped.2018.00431

15. Bilginturan N. Treatment of childhood obesity, Katkı Journal of Pediatrics 2000;21:527-36.

16. Mo-Suwan L, Geater AF. Risk factors for childhood obesity in a transitional society in Thailand. International Journal of Obesity (United Kingdom). 1996;697-703.

17. Gürel S, İnan G. Childhood obesity diagnostic methods, prevalence and etiology. ADÜ Medicine Journal 2001;2:39-46.

18. Dorosty AR, Emmett PE, Cowin AS, Reilly JJ, ALSPAC Study Team. Factors Associated With Early Adiposity Rebound. Ahmad. Pediatrics 2000;105:1115-8. https://doi.org/10.1542/peds.105.5.1115

19. Yılmaz D. In children, obesity may be used in diagnostic methods and their relationship. Specialist thesis. Aydın 2006.

20. Anderson SE, Keim SA. Parent-child interaction, selfregulation, and obesity prevention in early childhood Curr Obes Rep. 2016;5:192-200. https://doi.org/10.1007/s13679-016-0208-9

21. Adab P, Pallan MJ, Lancashire ER, Hemming K, Frew E, Barrett $T$, et al. Effectiveness of a childhood obesity prevention programme delivered through schools, targeting 6 and 7 year olds: cluster randomised controlled trial (WAVES study). BMJ. 2018;7;360:k211. https://doi.org/10.1136/bmj.k211 
22. August GP, Caprio S, Fennoy I, Freemark M, Kaufman $\mathrm{FR}$, Lusting $\mathrm{RH}$, et al. Prevention and treatment of pediatric dbesity: An andocrine society çlinical practice guideline based on expert opinion. J Clin Endocrinol Metab. December 2008;93:4576-99.

https://doi.org/10.1210/jc.2007-2458

23. Barlow SE. Expert Commitee Recommendations regarding the prevention, assassment, and treatment of child and adolescent overweight and obesity: Summary Report Pediatric 2007;120:164-92. https://doi.org/10.1542/peds.2007-2329C

24. Algorithm for the Assessment and Management of Childhood Obesity in Patients 2 Years and Older This algorithm is based on the 2007 Expert Committee Recommendations, 1 new evidence and promising practices. 